\title{
Letter to the Editor concerning "Gene expression analysis in chronic postradiation proctopathy" by Traub et al. (Int J Colorectal Dis 27:879-884, 2012)
}

\author{
Johannes Jongen • Volker Kahlke • Sven Petersen
}

Accepted: 26 July 2012 / Published online: 9 August 2012

(C) Springer-Verlag 2012

\section{Dear Editor:}

With interest, we read the paper by Traub et al. providing important information on the molecular mechanism of radiation-induced proctitis. Nevertheless, we would like to use the opportunity to address a word of caution from a more clinical point of view according to the potential danger of biopsies in the irradiated rectum.

Biopsies of the rectal wall in preirradiated tissue might cause devastating complications. For example, Shakespeare et al. [1] described six patients with a recto-urethral fistula after brachytherapy for prostate cancer. Three of these patients developed the fistula 3-4 months after transrectal biopsy. Performing invasive procedures in radiated and severely contaminated tissue may cause severe infectious complications as well as non- or slow-healing ulcerating wounds [2]. Theodorescu et al. [3] also pointed out the risk of severe complications after invasive procedures such as biopsies.

Traub et al. reported that patients were selected based on the following parameters: (1) after radiotherapy for cervical or prostate cancer, (2) LENT/RTOG grade 3/4, and (3) acute

\section{J. Jongen $(\bowtie) \cdot$ V. Kahlke}

Proctological Office, Department of Surgical Proctology,

Park-Klinik Kiel,

Kiel, Germany

e-mail: j.jongen@kielnet.net

\section{S. Petersen}

Department of General and Visceral Surgery,

Asklepios Hospital Altona,

Hamburg, Germany rectal bleeding with the need of endoscopic evaluation/treatment. Biopsies were taken from the affected rectum (ventral and dorsal part).

For patients having a history of radiotherapy in the pelvic region, we would recommend that invasive procedures, such as biopsies in the anorectal region, should be avoided because of the above-mentioned complications. If a biopsy is needed to exclude malignancy, in our opinion, this should be done only after all noninvasive procedures have been done, and these could not rule out malignancy. Others also have these recommendations [4]. Thus, we were quite amazed that biopsies were taken for research purposes. Patients need to be aware prior to endoscopy that even small biopsy lesions might lead to long-lasting complications and consecutive treatment. In this context, biopsies for research on postradiation proctopathy remain questionable.

\section{References}

1. Shakespeare D, Mitchell DM, Carey BM, Finan P, Henry AM, Ash D, Bottomley DM, Al-Qaisieh B (2007) Recto-urethral fistula following brachytherapy for localized prostate cancer. Colorectal Dis 9:328-331

2. Hayne D, Vaizey CJ, Boulos PB (2001) Anorectal injury following pelvic radiotherapy. Br J Surg 88:1037-1048

3. Theodorescu D, Gillenwater JY, Koutrouvelis PG (2000) Prostatourethral-rectal fistula after prostate brachytherapy. Cancer 89:2085-2091

4. Phan J, Swanson DA, Levy LB, Kudchadker RJ, Bruno TL, Frank SJ (2009) Late rectal complications after prostate brachytherapy for localized prostate cancer: incidence and management. Cancer 115:1827-1839 